\title{
Comparison of Agglomeration Behavior of Fine Particles in Liquid among Various Mixing Operations
}

\author{
Syunsuke SUMITOMO, Kota YOSHITOMI, Md. Azhar UDDIN and Yoshiei KATO* \\ Graduate School of Environmental and Life Science, Okayama University, 1-1 Tsushima-naka, 3-chome, Kita-ku, Okayama, \\ 700-8530 Japan.
}

(Received on April 6, 2017; accepted on August 23, 2017)

\begin{abstract}
In order to compare the agglomeration and breakup behavior of fine particles in liquid by various mixing operations, model experiments were carried out and a mathematical model was developed and compared with the experimental results. Three kinds of mixing operations were examined: mechanical stirring by impeller (impeller), gas blow mixing (gas), and gas and liquid jet blow mixing by $\mathrm{RH}$ degasser $(\mathrm{RH})$. Polymethylmethacrylate (PMMA) particles of $2.8 \times 10^{-6} \mathrm{~m}$ in mean diameter and $3.0 \times 10^{3} \mathrm{~mol} \cdot \mathrm{m}^{-3}$ of $\mathrm{KCl}$ solution were used in the experiment as solid and liquid phases, respectively. Total number of PMMA particles at each mixing process decreased with the increasing time, although the agglomeration rate decreased. The PMMA agglomeration rate at the same mixing energy input in the liquid was in the following decreasing order: impeller, gas, and $\mathrm{RH}$ mixing. The experimental results of the impeller mixing were able to be explained by a turbulence agglomeration model. A breakup model of particles was newly developed assuming that the agglomerated PMMA particles adhered to the surface of bubbles during bubble floating in the liquid was divided into two pieces on the gas/liquid free surface at the moment of bubble bursting. By introducing this breakup model in addition to the agglomeration one, the calculation results for both of the gas and $\mathrm{RH}$ mixing agreed well with the experiment.
\end{abstract}

KEY WORDS: particle agglomeration; particles breakup; mechanical stirring; gas blow mixing; RH degassing.

\section{Introduction}

It is important to remove nonmetallic inclusions from molten steel by agglomeration, coalescence and flotation ${ }^{1-5)}$ for the purpose of obtaining clean steel. Many experimental and theoretical studies have been done on the agglomeration behavior of fine particles in liquid: agglomeration structure by using a fractal dimension, ${ }^{6-11)}$ wettability of particles, ${ }^{12,13)}$ heterogeneous agglomeration with a different surface electrification and size ${ }^{14-18)}$ particle collision frequency in turbulent flow, ${ }^{19,20)}$ particle-size grouping. ${ }^{21)}$

However, there are few studies on comparison of the particle agglomeration behavior among various mixing operations, although it is indispensable for the optimal mixing operation and design. In this study, experiments were conducted for three kinds of mixing operations: mechanical stirring by impeller (impeller mixing), gas blow mixing (gas mixing), and gas and liquid mixing by $\mathrm{RH}$ degasser (RH mixing) in order to compare the agglomeration rate of fine particles among three mixing operations. The theoretical model on the particle agglomeration coexisting with the breakage of particles was next developed and evaluated. There were some theoretical and experimental studies on the particle breakup by particles collision ${ }^{22,23)}$ and fluid

* Corresponding author: E-mail: y-kato@cc.okayama-u.ac.jp DOI: http://dx.doi.org/10.2355/isijinternational.ISIJINT-2017-190 shear stress, ${ }^{23,24)}$ however, the particle breakup of gas stirring was not treated there. Therefore, in this study, we developed a theoretical model considering not only particle agglomeration but also breakup of agglomerated particles adhered to bubbles during bubble bursting for the gas and $\mathrm{RH}$ mixing and compared with the experimental results. Here, RH degasser is a vacuum degassing device utilized at the secondary steel refining in steelmaking field. Molten steel in lower vessel is sucked in the upper vacuum vessel and circulated between the upper and lower vessels by the effect of bubble lift pump where argon gas is blown through a connected tube ${ }^{25,26)}$ as shown later in Fig. 1.

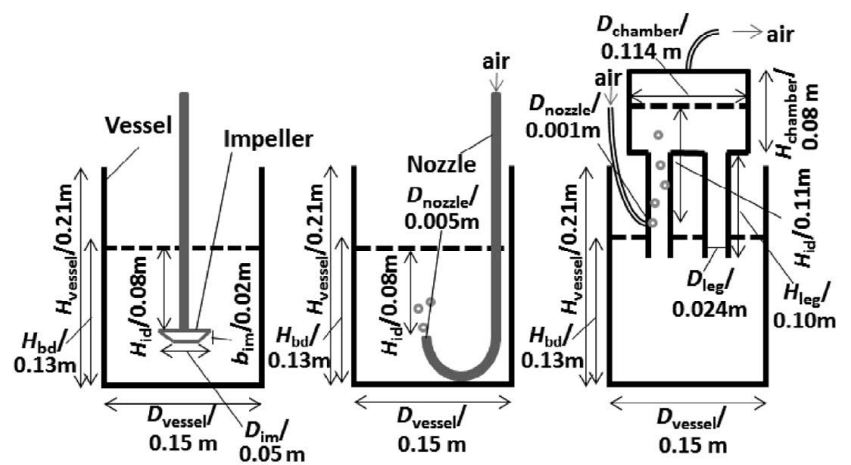

(a) Impeller

(b) Gas

(c) $\mathrm{RH}$

Fig. 1. Experimental apparatuses of impeller, gas and RH mixing. 


\section{Experimental Setup}

\subsection{Experimental Apparatus}

Figure 1 shows the experimental apparatuses of the impeller, gas and RH mixing. The same size of cylindrical and acrylic vessel (diameter, $D_{\text {vessel }} ; 0.15 \mathrm{~m}$, height, $H_{\text {vessel }} ; 0.21$ $\mathrm{m}$ ) was used for the experiment. Volume, $V$, of $\mathrm{KCl}$ solution in the vessel was also fixed to $2.0 \times 10^{-3} \mathrm{~m}^{3}$ and bath depth, $H_{\text {bd }}$, became $0.13 \mathrm{~m}$. For the impeller mixing, paddle type of impeller (width, $d_{\text {im }} ; 5.0 \times 10^{-2} \mathrm{~m}$, thickness, $b_{\text {im }} ; 2.0 \times 10^{-2}$ $\mathrm{m}$, number of blade; 2 ) was used and the impeller immersion depth, $H_{\text {id }}$ was kept to $8.0 \times 10^{-2} \mathrm{~m}$. The gas blow mixing was made by a nozzle (inner diameter, $D_{\text {nozzle }} ; 5.0 \times 10^{-3} \mathrm{~m}$ ), and nozzle immersion depth, $H_{\mathrm{id}}$, was $8.0 \times 10^{-2} \mathrm{~m}$. For the RH mixing, chamber diameter, $D_{\text {chamber, }}$ and height, $H_{\text {chamber, }}$ were 0.114 and $0.080 \mathrm{~m}$, respectively. Leg diameter, $D_{\text {leg }}$ and height, $H_{\text {leg }}$, were 0.024 and $0.10 \mathrm{~m}$, respectively. Nozzle immersion depth, $H_{\text {id }}$, between nozzle tip and chamber free surface was $0.11 \mathrm{~m}$, and nozzle diameter, $D_{\text {nozzle }}$, of the leg was $1.0 \times 10^{-3} \mathrm{~m}$. Volume of $\mathrm{KCl}$ solution including legs and chamber was $5.0 \times 10^{-4} \mathrm{~m}^{3}$.

\subsection{Methods}

Polymethylmethacrylate (PMMA) (Sekisui Plastics Co., Ltd.) particles of $2.8 \times 10^{-6} \mathrm{~m}$ in mean diameter were used as a model particle. First, a given number of PMMP particles were put into a small amount of ion-exchanged water and almost thoroughly dispersed with an ultrasonic cleaner (Branson, Series 8500 ). $3.0 \times 10^{3} \mathrm{~mol} \cdot \mathrm{m}^{-3}$ of $\mathrm{KCl}$ solution was used to obtain the rapid particle agglomeration condition by making thinner electric double layer around the particles and causing the negligible repulsion between particles. The experiment started when particles-including water was charged into the $\mathrm{KCl}$ solution. The sampling times were 0 , $1,2,4,10,30,60,120$ and $180 \mathrm{~min}$, and the sampling point was set to $0.020 \mathrm{~m}$ apart from the center axis of the vessel and $0.05 \mathrm{~m}$ high from the bottom of the vessel. $1.0 \times 10^{-6}$ $\mathrm{m}^{3}$ of particle-suspended liquid was taken in a single sampling. The temporal changes in number of agglomerated particles and size distribution were measured by a particle size distribution analyzer (Beckman Coulter, Inc., Multisizer $3)$. The particle size measured here was volume-equivalent diameter. The initial total number density of particle in $\mathrm{KCl}$ solution was $2.1 \times 10^{12}-2.6 \times 10^{12} \mathrm{~m}^{-3}$. Physical properties of PMMA particle and $\mathrm{KCl}$ solution are shown in Table 1.

\subsection{Calculation of Energy Input Rate of Mixing Energy into Liquid Bath}

The energy input rate, $P\left[\mathrm{~W} \cdot \mathrm{kg}^{-1}\right]$, of mixing into liquid bath was calculated to compare the agglomeration behavior between three kinds of mixing pattern at the same $P$ value.

$P$ of the impeller mixing is given by $\operatorname{Nagata}^{27)}$ as follows:

$$
\begin{aligned}
& P=N_{\mathrm{p}} \rho_{\mathrm{L}} R_{\mathrm{s}}{ }^{3} d_{\mathrm{im}}{ }^{5} \\
& N_{\mathrm{p}}=\frac{A}{\operatorname{Re}}+B\left(\frac{10^{3}+1.2 R e^{0.66}}{10^{3}+3.2 R e^{0.66}}\right)^{C}\left(\frac{H_{\mathrm{bd}}}{D_{\text {vessel }}}\right)^{0.35+\frac{b_{\text {im }}}{D_{\text {vessel }}}}
\end{aligned}
$$

Table 1. Physical properties of particle and liquid used for the experiment.

\begin{tabular}{ccc}
\hline PMMA particle & Mean diameter $[\mathrm{m}]$ & $2.8 \times 10^{-6}$ \\
& Density, $\rho_{\mathrm{P}}\left[\mathrm{kg} \cdot \mathrm{m}^{-3}\right]$ & $1.20 \times 10^{3}$ \\
& Hamaker constant, $A_{131}[\mathrm{~J}]$ & $1.05 \times 10^{-20}$ \\
\hline Liquid & $\mathrm{KCl}$ concentration, $C\left[\mathrm{~mol} \cdot \mathrm{m}^{-3}\right]$ & $3.0 \times 10^{3}$ \\
& Density, $\rho_{\mathrm{L}}\left[\mathrm{kg} \cdot \mathrm{m}^{-3}\right]$ & $1.13 \times 10^{3}$ \\
& Viscosity, $\mu[\mathrm{Pa} \cdot \mathrm{s}]$ & $9.27 \times 10^{-4}$ \\
\hline
\end{tabular}

Table 2. Operating variables at the same energy input rate into liquid.

\begin{tabular}{ccccc}
\hline & Power $\left[\mathrm{W} \cdot \mathrm{kg}^{-1}\right]$ & 0.021 & 0.027 & 0.035 \\
Impeller & $R_{\mathrm{m}}[\mathrm{rpm}]$ & 250 & 275 & 300 \\
Gas & $Q_{\mathrm{g}}\left[\mathrm{L} \cdot \mathrm{min}^{-1}\right]$ & 1.5 & 2.0 & 2.5 \\
$\mathrm{RH}$ & $Q_{\mathrm{RH}}\left[\mathrm{L} \cdot \mathrm{min}^{-1}\right]$ & 1 & 1.5 & 2 \\
\hline
\end{tabular}

$$
\begin{gathered}
A=14\left(\frac{b_{\text {im }}}{D_{\text {vessel }}}\right)\left\{670\left(\frac{d_{\text {im }}}{D_{\text {vessel }}}-0.6\right)^{2}+185\right\} \ldots \ldots . . \\
B=10^{\left\{1.3-4\left(\frac{b_{\text {im }}}{D_{\text {vessel }}}-0.5\right)^{2}-1.14\left(\frac{d_{\text {im }}}{D_{\text {vessel }}}\right)\right\} \ldots \ldots \ldots \ldots . . . . . . . . . . . ~} \\
C=1.1+4\left(\frac{b_{\text {im }}}{D_{\text {vessel }}}\right)-2.5\left(\frac{d_{\text {im }}}{D_{\text {vessel }}}-0.5\right)^{2}-7\left(\frac{b_{\text {im }}}{D_{\text {vessel }}}\right)^{4} \ldots
\end{gathered}
$$

where $N_{\mathrm{p}}$ is number of power [-], $R_{\mathrm{s}}$ is rotation speed [ $\left.\mathrm{s}^{-1}\right]$ and $R e$ is Reynolds number [-]. The other symbols are shown in Fig. 1.

$P$ of gas and RH mixing is the energy rate given by buoyancy force of bubble during floatation and expressed by Eq. (6). ${ }^{28)}$

$$
P=3.97 \times 10^{-3} T \log \left(1+\frac{H_{\text {id }}}{10.3}\right)
$$

where $Q_{\mathrm{B}}$ : injected gas flow rate $\left[\mathrm{m}^{3} \cdot \mathrm{s}^{-1}\right], T$ : liquid temperature $[\mathrm{K}]$.

Table 2 shows the operating variables at the same energy input rate into liquid for three kinds of mixing operations. $P$ value was changed to $0.021,0.027$ and $0.035 \mathrm{~W} \cdot \mathrm{kg}^{-1}$. Gas flow rate of RH is less than that of gas mixing due to longer immersion depth, $H_{\text {id }}$.

\section{Experimental Results}

\subsection{Change in Particle Distribution with Time}

Figure 2 shows the temporal change in number distribution of particles normalized by the initial total number of particles. The mixing pattern was mechanical stirring and rotation speed was fixed to $250 \mathrm{rpm}$. The peak of number of particles in agglomerated cluster of 1, that is no agglomeration, was largest in all. However, particles agglomerated with each other and the peaks of agglomerated particles appeared with time. 
Number of particles in agglomerated cluster [-]

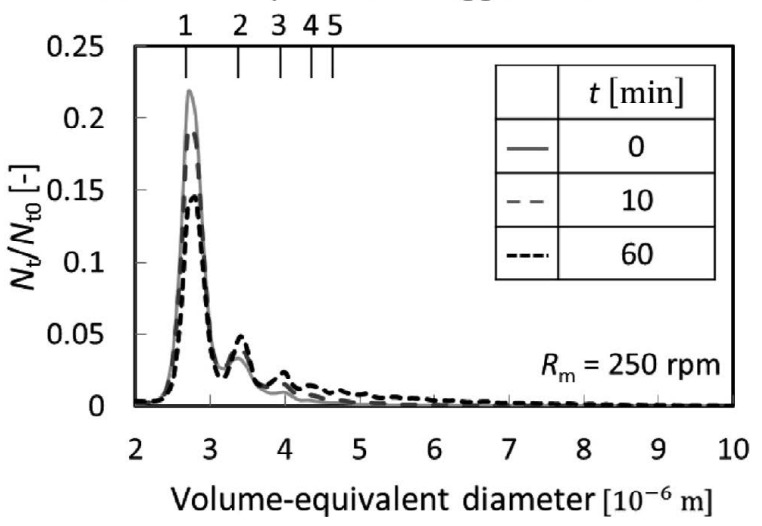

Fig. 2. Change in particle size distribution with time for impeller mixing.

\subsection{Change in Number of Particles with Time for Each Mixing Pattern}

The temporal change in number of total particles with and without agglomeration normalized by the initial particle number for impeller, gas and RH mixing is shown in Fig. 3. The number of particles for all mixing practices decreased with time, which indicated the agglomeration of particles. Now, we focused on the agglomeration rate defined by the decreasing number of particles per unit time. For the impeller and RH mixing, the larger energy input rate caused the more rapid agglomeration rate until about $60 \mathrm{~min}$, although there was no marked change in gas mixing. The number of particles in RH mixing reversed after about 120 min, that is, the agglomeration rate decreased with the increase in the energy input.
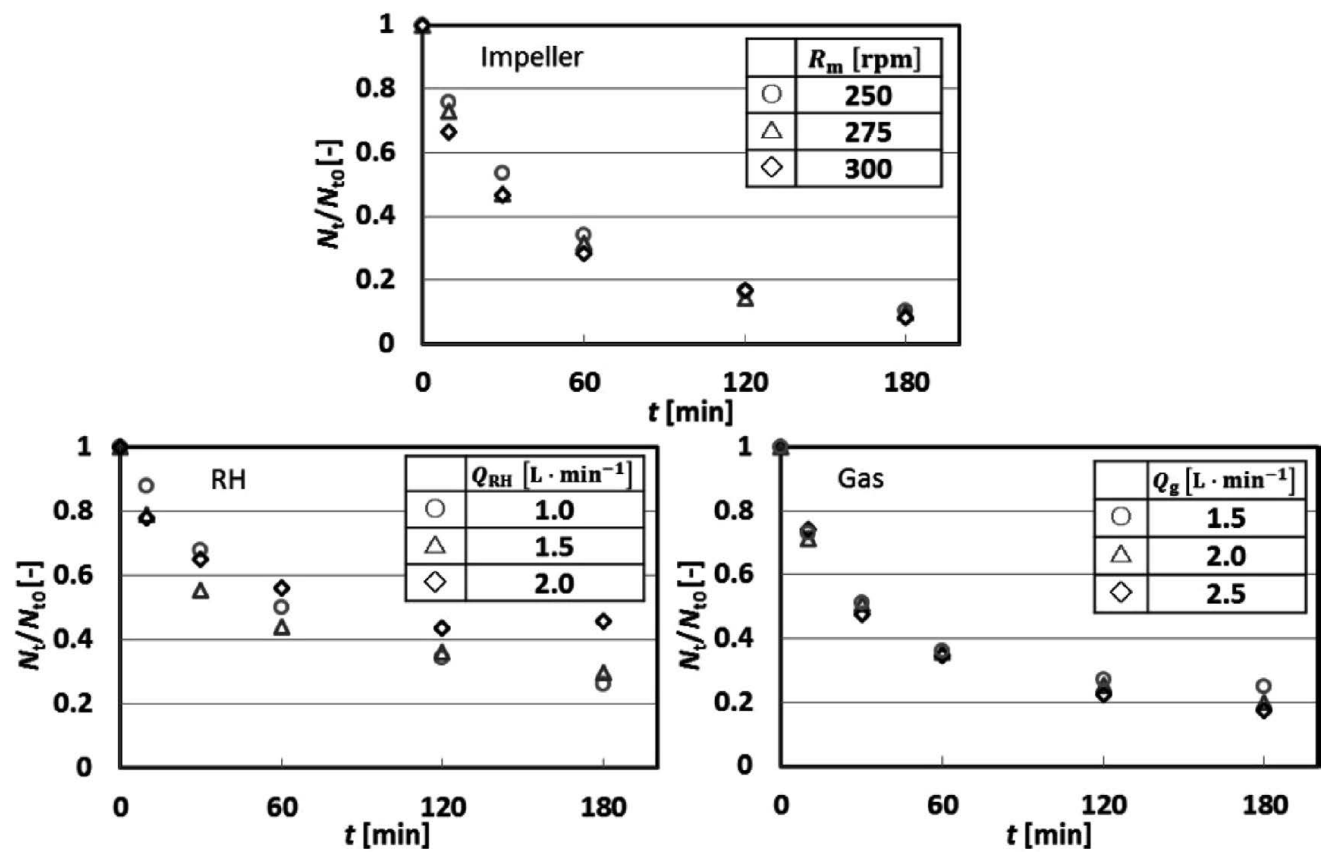

Fig. 3. Change in number of particles with time for impeller, gas and RH mixing.

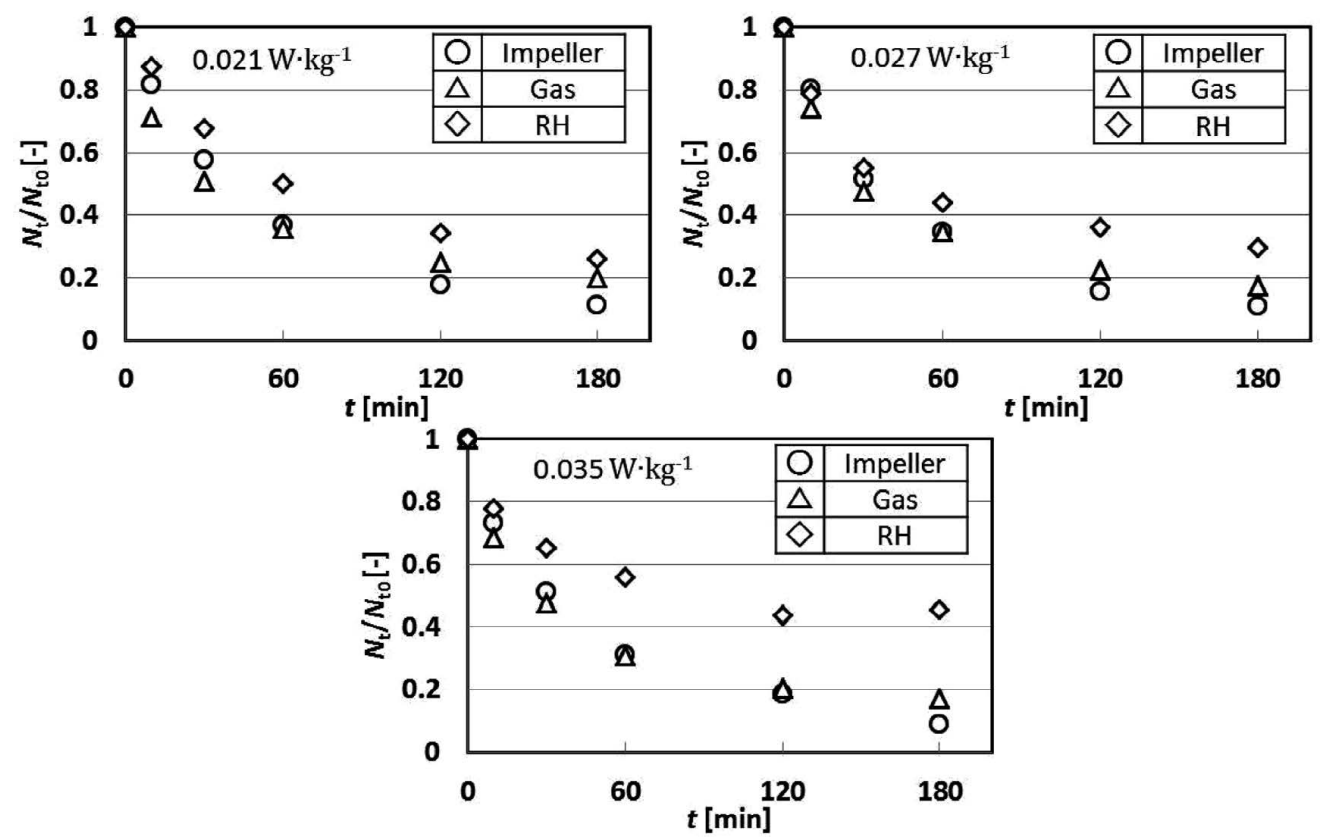

Fig. 4. Change in number of particles with time at the same energy input rate into liquid. 


\subsection{Change in Number of Particles with Time at the Same Energy Input Rate into Liquid}

Figure 4 shows the comparison of the normalized number of total particles by the initial one among the impeller, gas and RH mixing. The energy input rate was changed to $0.021,0.027$ and $0.035 \mathrm{~W} \cdot \mathrm{kg}^{-1}$. The agglomeration rate at the same mixing energy input was in the following decreasing order: impeller, gas, and $\mathrm{RH}$ mixing. We assumed that the effective agglomeration rate of the gas and $\mathrm{RH}$ mixing was smaller than that of impeller mixing due to breakup of a part of agglomerated particles. The breakup is estimated to be attributable to gas bubbles which do not exist for the impeller mixing.

\section{Theoretical Agglomeration Model and its Compari- son with Experimental Results}

\subsection{Agglomeration and Breakup Model}

\subsubsection{Agglomeration Rate}

The agglomeration behavior of particles is explained by a discrete population balance and collision frequency function between two particles. ${ }^{29)}$ Assuming that the agglomeration occurs by the collision of $\mathrm{i}$-and $\mathrm{j}$ - agglomerated particles, the number of collisions per second and per cubic meter is expressed by the product of collision frequency function, $\alpha\left(a_{\mathrm{i}}, a_{\mathrm{j}}\right)\left[\mathrm{m}^{3} \cdot \mathrm{s}^{-1}\right]$, of clusters of $\mathrm{i}$ - and $\mathrm{j}$ - particles, number density, $N_{\mathrm{i}}\left[\mathrm{m}^{-3}\right]$, and $N_{\mathrm{j}}\left[\mathrm{m}^{-3}\right]$, of cluster of i- and j- particles. Here, $a_{\mathrm{i}}$ and $a_{\mathrm{j}}$ are volumetric equivalent radii of cluster of $\mathrm{i}$ - and $\mathrm{j}$ - particles $[\mathrm{m}]$, respectively.

Then, the time-derivative of number density, $N_{\mathrm{k}}\left[\mathrm{m}^{-3}\right]$, of k- particles is given by Eq. (7) where the first and second items of the right side represent the formation and disappearance rates of cluster of $k$ - particles by the collision of $i$ and $\mathrm{j}$ - particles, and $\mathrm{i}$ and $\mathrm{k}$ - particles, respectively.

$$
\frac{d N_{\mathrm{k}}}{d t}=\frac{1}{2} \sum_{\mathrm{i}=1, \mathrm{i}+\mathrm{j}=\mathrm{k}}^{\mathrm{i}=\mathrm{k}-1} \alpha\left(a_{\mathrm{i}}, a_{\mathrm{j}}\right) N_{\mathrm{i}} N_{\mathrm{j}}-\sum_{\mathrm{i}=1}^{\mathrm{Max}} \alpha\left(a_{\mathrm{i}}, a_{\mathrm{k}}\right) N_{\mathrm{i}} N_{\mathrm{k}}
$$

The collision frequency function, $\alpha\left(a_{\mathrm{i}}, a_{\mathrm{j}}\right)$, of fine particles in Eq. (7) under turbulent flow was introduced by SaffmanTurner. ${ }^{30)}$

$$
\alpha\left(a_{\mathrm{i}}, a_{\mathrm{j}}\right)=1.3\left(a_{\mathrm{i}}+a_{\mathrm{j}}\right)^{3}\left(\frac{\varepsilon}{v}\right)^{\frac{1}{2}}
$$

where $\varepsilon$ is dissipation rate of turbulence energy $\left[\mathrm{m}^{2} \cdot \mathrm{s}^{-3}\right]$ and $v$ is coefficient of kinetic viscosity $\left[\mathrm{m}^{2} \cdot \mathrm{s}^{-1}\right]$. Considering the effect of London-van der Waals force based on liquid viscosity and electric polarization between particles, ${ }^{31)} \mathrm{Eq}$. (8) is corrected by agglomeration efficiency, $Z$, as follows.

$$
\begin{aligned}
& \alpha\left(a_{\mathrm{i}}, a_{\mathrm{j}}\right)=1.3 Z\left(a_{\mathrm{i}}+a_{\mathrm{j}}\right)^{3}\left(\frac{\varepsilon}{v}\right)^{\frac{1}{2}} \\
& Z=0.727\left[\frac{\mu a_{1}^{3}\left(\frac{\varepsilon}{v}\right)^{\frac{1}{2}}}{A_{131}}\right]^{-0.242}
\end{aligned}
$$

where $\mu$ is viscosity and $A_{131}$ is Hamarker constant [J] when suffix 1 means particle and 3 liquid.

Substituting Eqs. (8') and (9) into (7), number of a given cluster of k- particles is calculated under the initial condition.

\subsubsection{Introduction of Breakup Item}

As described in chapter 3, the agglomeration rate of the gas and RH mixing was less than that of the impeller mixing at the same energy input rate into liquid. Thus, we assumed that bubbles of the gas and $\mathrm{RH}$ mixing divided partly the agglomerated particles and reduced the net agglomeration rate. Figure 5 shows the schematic image of particle breakup in the liquid. Various clusters of particles adhere to gas bubbles during floating in the liquid ${ }^{32,33)}$ and they are divided into smaller particles in connection with bubble bursting at the free surface. Here, the bubble adhesion was not observed. On the other hand, we assumed that the impeller mixing in this study had no influence on the breakup of agglomerated particles because the rotation speed was not so high.

Introducing the breakup items for the gas and RH mixing, the time-derivative of number density, $N_{\mathrm{k}}\left[\mathrm{m}^{-3}\right]$, of cluster of k- particles is expressed as Eq. (10) where the first and second terms of the right side result from the gross agglomeration as shown in Eq. (7) and the third and fourth terms indicate the breakup of agglomerated particles. As shown in Eq. (10), each particle is assumed to be divided into two parts at bubble bursting.

$$
\begin{aligned}
\frac{d N_{\mathrm{k}}}{d t}= & \frac{1}{2} \sum_{\substack{\mathrm{i}=1, \mathrm{i}+\mathrm{j}=\mathrm{k}}}^{\mathrm{i}=\mathrm{k}-1} \alpha\left(a_{\mathrm{i}}, a_{\mathrm{j}}\right) N_{\mathrm{i}} N_{\mathrm{j}}-\sum_{\mathrm{i}=1}^{\mathrm{Max}} \alpha\left(a_{\mathrm{i}}, a_{\mathrm{k}}\right) N_{\mathrm{i}} N_{\mathrm{k}} \\
& +\sum_{\mathrm{i}=\mathrm{k}+1}^{\mathrm{Max}} \chi_{\mathrm{kli}} \beta\left(a_{\mathrm{i}}, d_{\mathrm{B}}\right) N_{\mathrm{i}} N_{\mathrm{B}}-\beta\left(a_{\mathrm{i}}, d_{\mathrm{B}}\right) N_{\mathrm{k}} N_{\mathrm{B}}
\end{aligned}
$$

where $\beta\left(a_{\mathrm{i}}, d_{\mathrm{B}}\right)$ is breakup frequency function by bubble bursting $\left[\mathrm{m}^{3} \cdot \mathrm{s}^{-1}\right], d_{\mathrm{B}}$ is mean bubble diameter $[\mathrm{m}], N_{\mathrm{B}}$ is number density of bubbles $\left[\mathrm{m}^{-3}\right]$, and $\chi_{\mathrm{k} \mid \mathrm{i}}$ is breakup distribution function defined as volumetric ratio of cluster of k- particles obtained from the breakup of cluster of i- particles. The $d_{\mathrm{B}}$ and $N_{\mathrm{B}}$ values in Eq. (10) are obtained from the following section.

We assumed that $\beta\left(a_{\mathrm{i}}, d_{\mathrm{B}}\right)$ was composed of the product of two items: one was the frequency function, $\gamma\left[\mathrm{m}^{3} \cdot \mathrm{s}^{-1}\right]$, of particles adherence to bubbles and the other was the breakup

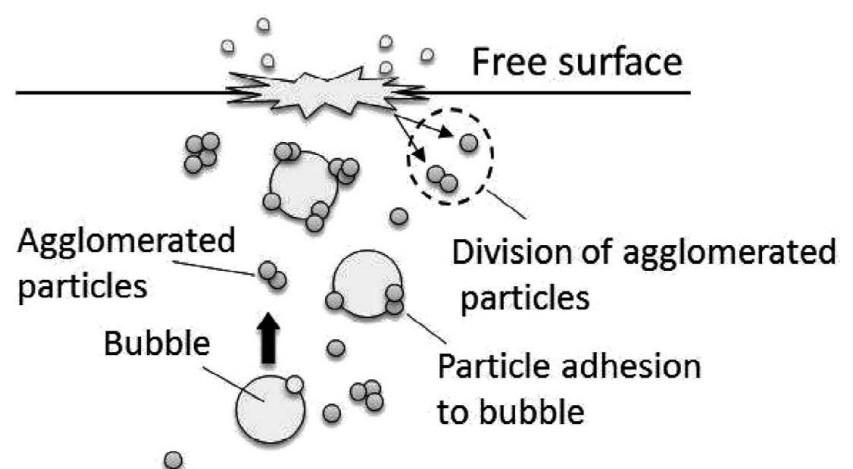

Fig. 5. Schematic image of particle adhesion to bubble during floating and agglomerated particle breakup at bubble bursting. 
efficiency, $\delta$ [-], of adhering particles at the bubble bursting, as expressed by Eq. (11).

$$
\beta\left(a_{\mathrm{i}}, d_{\mathrm{B}}\right)=\gamma \cdot \delta
$$

Equation (12), which was introduced by Arai et al., ${ }^{34)}$ was used as the $\gamma$ item, whereas we expressed $\delta$ as the function of non-dimensional particle number, bubble diameter and bubble number so as to obtain the constant parameter, $\mathrm{K}$, by Eq. (13).

$$
\begin{array}{r}
\gamma=\frac{\pi\left(a_{\mathrm{i}}+d_{\mathrm{B}}\right)^{2}}{4} u_{\mathrm{B}} \cdot A\left(\frac{a_{\mathrm{i}}}{d_{\mathrm{B}}}\right) \varepsilon^{-B} \frac{1}{1+\exp \left[-L\left(\theta-\theta_{\mathrm{i}}\right)\right]} \ldots \\
\delta=K \cdot i^{\frac{5}{3}}\left(\frac{d_{\mathrm{B}}}{a_{1}}\right)^{5}\left(\frac{N_{\mathrm{B}}}{N_{\mathrm{t} 0}}\right)^{2} \ldots \ldots \ldots \ldots \ldots \ldots \ldots \ldots \ldots \ldots \ldots \ldots
\end{array}
$$

where $u_{\mathrm{B}}$ is bubble floating velocity [m/s], $\theta$ is contact angle, $A(=0.57), B(=0.21), L(=3.5)$ and $\theta_{i}(=88)$ are constant. As described in 4.2.2, breakup factor, $K$ becomes $=150$.

The assumption of binary breakup of agglomerated particles leads to $\chi_{\mathrm{k} \mid \mathrm{i}}$ expressed by Eq. (14)

$$
\chi_{\mathrm{kli}}=\frac{1}{i-1}
$$

\subsubsection{Bubble Diameter and Number Density}

Bubble frequency, $f_{\mathrm{B}}\left[\mathrm{s}^{-1}\right]$, of the gas and RH mixing was observed by a video camera and the mean bubble diameter was calculated from Eq. (15). ${ }^{35)}$

$$
d_{\mathrm{B}}=\left(\frac{6 Q_{\mathrm{B}}}{\pi f_{\mathrm{B}}}\right)^{\frac{1}{3}}
$$

where, $Q_{\mathrm{B}}$ is gas flow rate $\left[\mathrm{m}^{3} \cdot \mathrm{s}^{-1}\right]$.

Figure 6 shows the relationship between $d_{\mathrm{B}}$ and gas flow rate, $Q_{\mathrm{g}}\left[\mathrm{L} \cdot \mathrm{min}^{-1}\right]$, of the gas mixing or gas flow rate, $Q_{\mathrm{RH}}$ $\left[\mathrm{L} \cdot \mathrm{min}^{-1}\right]$, of the $\mathrm{RH}$ mixing in addition to the empirical Eq. (16). ${ }^{36,37)}$

$$
d_{\mathrm{B}}=0.54\left(Q_{\mathrm{B}} D_{\text {nozzle }}{ }^{0.5}\right)^{0.289}
$$

where $D_{\text {nozzle }}$ is nozzle diameter [mm], and $5 \mathrm{~mm}$ for the gas mixing and $1 \mathrm{~mm}$ for the RH mixing in this study. As the results agreed well with them, their formula was applied for the calculation of $d_{\mathrm{B}}$.

On the other hand, as $f_{\mathrm{B}}$ is obtained from Eqs. (15) and (16) as follows,

$$
f_{\mathrm{B}}=12.1 Q_{\mathrm{B}}{ }^{0.133} D_{\text {nozzle }^{-0.434}}
$$

Number density, $N_{\mathrm{B}}$, of bubbles is expressed by Eq. (18).

$$
N_{\mathrm{B}}=\frac{f_{\mathrm{B}} H_{\mathrm{id}}}{V u_{\mathrm{B}}}
$$

where $V$ is water volume $\left[\mathrm{m}^{3}\right]$ and $H_{\text {id }}$ is floating distance of bubble $[\mathrm{m}]$ as shown in Fig. 1. Bubble floating velocity, $u_{\mathrm{B}}$ $\left[\mathrm{m} \cdot \mathrm{s}^{-1}\right]$, is given by Eq. (19) on condition that buoyancy and drag are equal. ${ }^{38)}$ In practice, we can use Eq. (19') due to $\rho_{\text {Liquid }} \gg \rho_{\text {Air }}$, where $\rho_{\text {Liquid }}$ and $\rho_{\text {Air }}$ are liquid and air density $\left[\mathrm{kg} \cdot \mathrm{m}^{-3}\right]$, respectively.
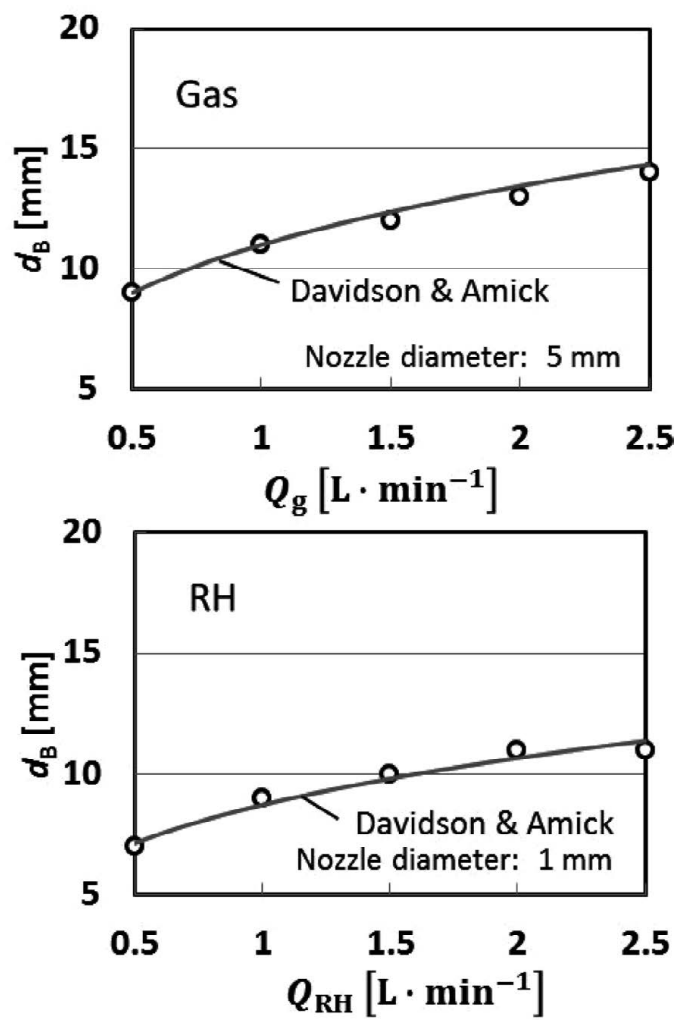

Fig. 6. Relationship between bubble diameter and gas flow rate for gas and $\mathrm{RH}$ mixing.

$$
\begin{gathered}
u_{\mathrm{B}}=\sqrt{\frac{4 g\left(\rho_{\text {Liquid }}-\rho_{\text {Air }}\right) d_{\mathrm{B}}}{3 C_{\mathrm{D}} \rho_{\text {Liquid }}}} \\
u_{\mathrm{B}}=\sqrt{\frac{4 g d_{\mathrm{B}}}{3 C_{\mathrm{D}}}} \ldots \ldots \ldots \ldots \ldots
\end{gathered}
$$

where $g$ is acceleration of gravity $\left[\mathrm{m} \cdot \mathrm{s}^{-2}\right], C_{\mathrm{D}}$ is drag coefficient [-] of which value is 0.44 at $500<R e<10^{5}$.

Thus, substituting Eqs. (16) and (18) into Eq. (10), temporal change in $N_{\mathrm{k}}$ for the gas and $\mathrm{RH}$ mixing can be calculated.

\subsubsection{Calculation Procedure}

The following non-dimensional Eqs. (20) and (21) were obtained from dividing Eq. (10) by $N_{\mathrm{k}}{ }^{*}, N_{\mathrm{B}}{ }^{*}$ and $t^{*}$ defined as Eqs. (22), (23) and (24), respectively.

$$
\begin{aligned}
& \frac{d N_{\mathrm{k}}{ }^{*}}{d t^{*}}=\frac{1}{2} \sum_{\mathrm{i}=1, \mathrm{i}+\mathrm{j}=\mathrm{k}}^{\mathrm{i}=\mathrm{k}-1}\left(\mathrm{i}^{\frac{1}{3}}+\mathrm{j}^{\frac{1}{3}}\right)^{3} N_{\mathrm{i}}{ }^{*} N_{\mathrm{j}}{ }^{*}-\sum_{\mathrm{i}=1}^{\mathrm{Max}}\left(\mathrm{i}^{\frac{1}{3}}+\mathrm{k}^{\frac{1}{3}}\right)^{3} N_{\mathrm{i}}{ }^{*} N_{\mathrm{k}}{ }^{*} \\
& +\sum_{\mathrm{i}=\mathrm{k}+1}^{\mathrm{Max}} \chi_{\mathrm{kli}} S \cdot \mathrm{i}^{2}\left[\frac{a_{\mathrm{i}}}{a_{1}}+\frac{d_{\mathrm{B}}}{a_{1}}\right]^{2} N_{\mathrm{i}}{ }^{*} N_{\mathrm{B}}{ }^{*}-S \cdot \mathrm{k}^{2}\left[\frac{a_{\mathrm{k}}}{a_{1}}+\frac{d_{\mathrm{B}}}{a_{1}}\right]^{2} N_{\mathrm{k}}{ }^{*} N_{\mathrm{B}}{ }^{*} \\
& \mathrm{~S}=51.6 \cdot \frac{d_{\mathrm{B}}{ }^{4} N_{\mathrm{B}}{ }^{2} u_{\mathrm{B}} v^{0.5}}{a_{1}{ }^{5} N_{\mathrm{t} 0}{ }^{2} \alpha \varepsilon^{0.71}} \cdot \frac{1}{1+\exp \left[-L\left(\theta-\theta_{\mathrm{i}}\right)\right]} \\
& N_{\mathrm{k}}{ }^{*}=\frac{N_{\mathrm{k}}}{N_{\mathrm{t} 0}}
\end{aligned}
$$




$$
\begin{array}{r}
N_{\mathrm{B}}{ }^{*}=\frac{N_{\mathrm{B}}}{N_{\mathrm{t} 0}} \ldots \ldots . . . \\
t^{*}=1.3 \alpha a_{1}{ }^{3}\left(\frac{\varepsilon}{v}\right)^{\frac{1}{2}} N_{\mathrm{t} 0} t
\end{array}
$$

where $N_{\text {to }}$ is the initial total number density of particles.

As seen in Fig. 2, the particle diameter of $10 \times 10^{-6} \mathrm{~m}$ which corresponded to the agglomerated particle number of $\left[\left(10 \times 10^{-6}\right) /\left(2.8 \times 10^{-6}\right)\right]^{3}=45.6$ was not almost observed in this study. Thus, we set MAX as 100 and $\Delta t^{*}$ as 0.0005 or 0.001 . Under the initial condition of Eq. (25) where $N_{\mathrm{k}, 0}$ indicates the initial number density of $\mathrm{k}$-particles $\left[\mathrm{m}^{-3}\right]$, the temporal change in $N_{\mathrm{k}}$ (k: 1 to MAX) was calculated numerically by Runge-Kutta method. The values of $N_{\mathrm{k}, 0}$ were obtained from Fig. 2.

$$
\left\{\begin{array}{l}
N_{1}=N_{1,0}=1.05 \times 10^{7}, N_{2}=N_{2,0}=1.58 \times 10^{6} \\
N_{3}=N_{3,0}=4.56 \times 10^{5}, N_{4}=N_{4,0}=2.00 \times 10^{5}, \ldots \\
N_{5}=N_{6}=\cdots=N_{99}=N_{100}=0
\end{array}\right.
$$

\subsection{Comparison between Calculation and Experimen- tal Results}

4.2.1. Temporal Change in Number of Particles for Impeller Mixing

Figure 7 shows the comparison of the temporal change in number from one to four clusters of particles between the calculated and experimental results for the impeller mixing. Rotation speed was $250 \mathrm{rpm}$. The calculated results agreed with the experimental ones. The change in number of clusters of all particles with time is shown in Fig. 8. The calculation also explained the experiment successfully. Thus, the
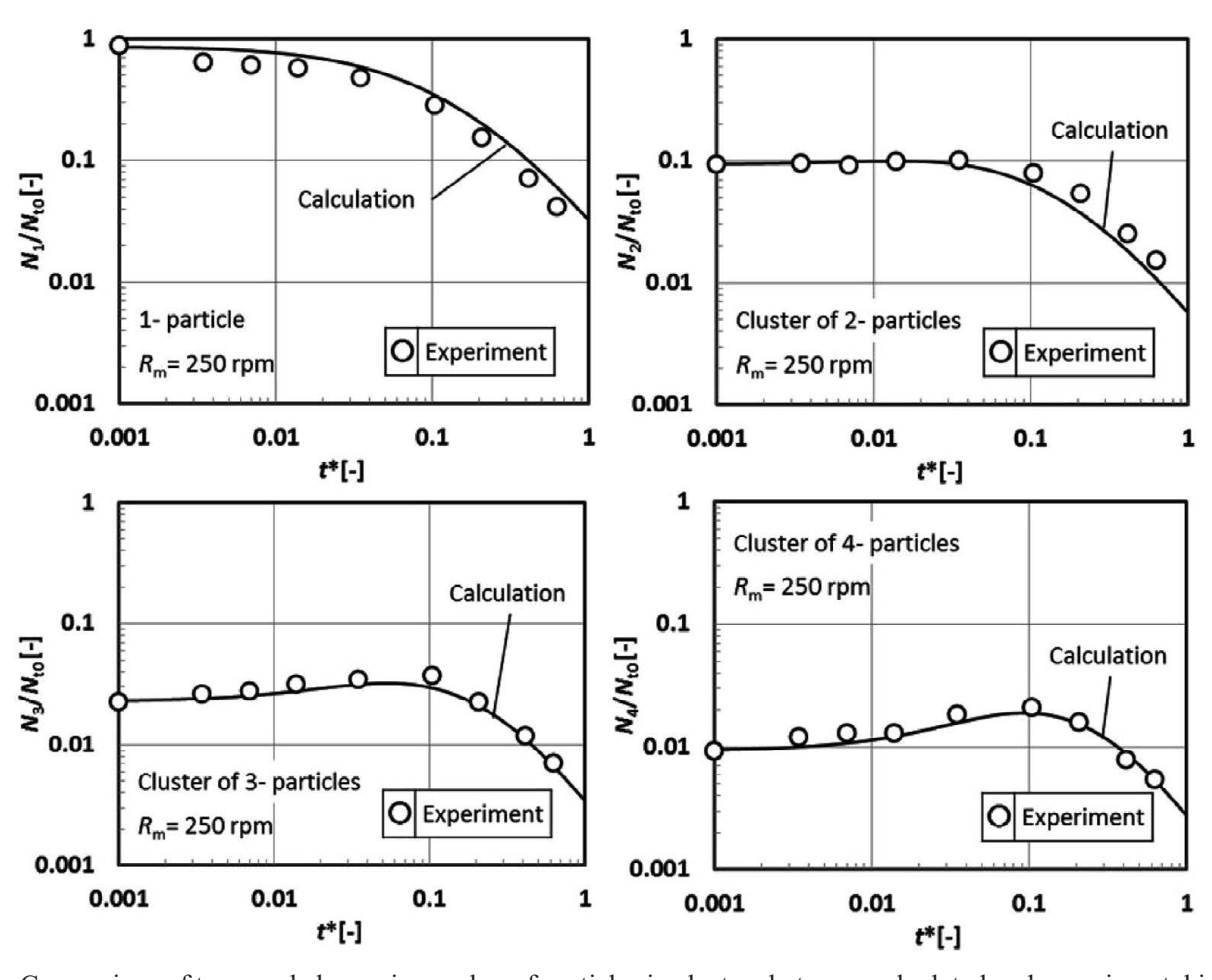

Fig. 7. Comparison of temporal change in number of particles in clusters between calculated and experimental impeller mixing. proceeded without breakup of particles. was $1.5 \mathrm{~L} \cdot \mathrm{min}^{-1}$. When the breakup factor, $K$, was 150 ,

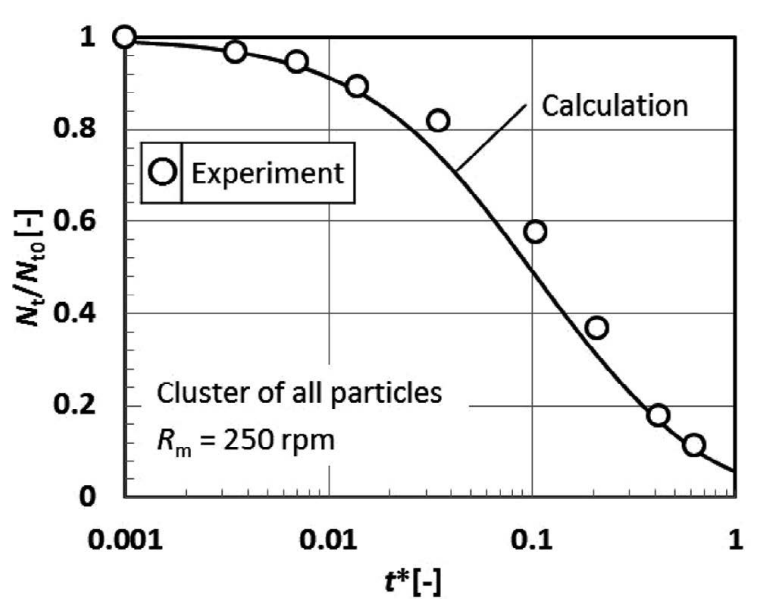

Fig. 8. Comparison of temporal change in number of clusters of mixing.

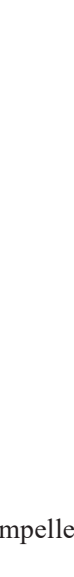

\subsubsection{Effect of Breakup Factor on Temporal Change in Agglomerated Particles}

We show that $K$ of 150 described in Section 4.1.2 is the optimal value. Figure 9 indicates the change in number of 1 particle, clusters of 2, 3, and 4 particles, and total cluster of all particles with time for the gas mixing. Gas flow rate the calculation fitted well to the experimental results. In the case of the RH mixing of $Q_{\mathrm{RH}}=1.0 \mathrm{~L} \cdot \mathrm{min}^{-1}$, the optimal $K$ value was also 150 as shown in Fig. 10. Thus, the breakup behavior of agglomerated particles for the gas and RH mixing was able to be explained by the breakup model that the adhering particles to the floating bubbles were divided at all particles between calculated and experimental impeller 

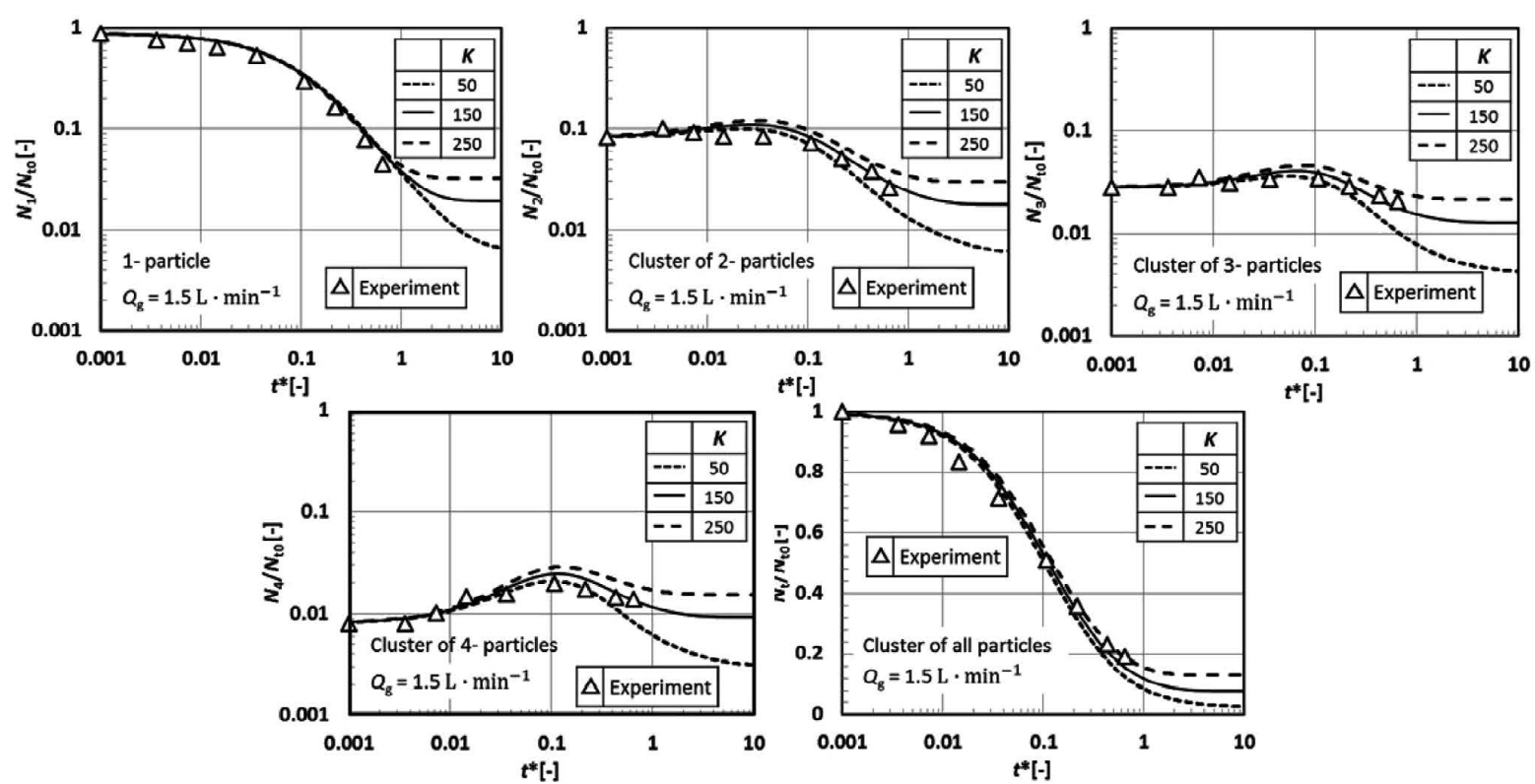

Fig. 9. Comparison of temporal change in number of particles in clusters between calculated and experimental gas mixing as a parameter of breakup factor.
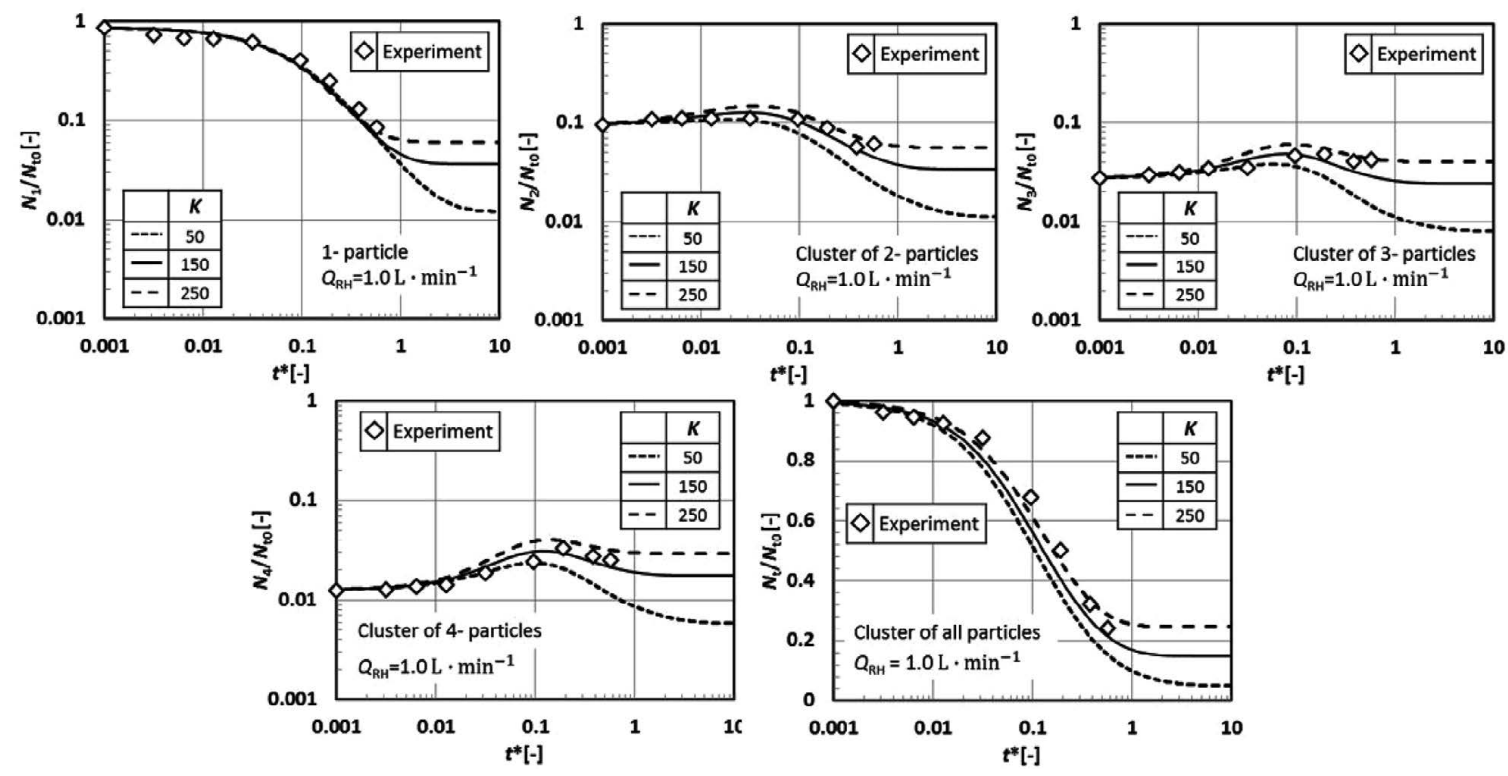

Fig. 10. Comparison of temporal change in number of particles in clusters between calculated and experimental $\mathrm{RH}$ mixing as a parameter of breakup factor.

the bubble bursting according to the function of Eq. (13). Figures 9 and 10, the agglomeration rate of particles was predicted to be decreased at $t^{*}>1$, although it was not verified by the experiment.

\subsubsection{Prediction of Agglomeration Behavior for Three Kinds of Mixing Process}

As shown in Sections 4.2.1 and 4.2.2, the calculated results agreed with experimental ones at $P=0.021 \mathrm{~W} \cdot \mathrm{kg}^{-1}$ as shown in Table 2. By using the same $K$ value $(=150)$, the temporal change in number, $N_{\mathrm{t}}$, of all particles was calculated and compared with the experiment under the other conditions. Figures 11 and $\mathbf{1 2}$ show the change in $N_{\mathrm{t}}$ with time at $P$ of 0.027 and $0.035 \mathrm{~W} \cdot \mathrm{kg}^{-1}$, respectively. For three kinds of mixing operation practices such as the impeller, gas and RH, the calculation agreed well with the experiment at the different $P$ values. Compared with the impeller mixing, the smaller agglomeration rates were reproduced for the gas and RH mixing by using the same breakup factor of $K=150$.

The agglomeration rate for the RH mixing was smaller than that for the gas mixing due to the larger breakup of agglomerated particles. Substituting Eqs. (11)-(13) and (16)-(19) into Eq. (11), $\beta\left(a_{\mathrm{i}}, d_{\mathrm{B}}\right)$ can be expressed by $d_{\text {nozzle }}$ as follows:

$$
\beta\left(a_{\mathrm{i}}, d_{\mathrm{B}}\right) \propto d_{\text {nozzle }}^{-0.073}
$$

As the nozzle diameters of the $\mathrm{RH}$ and gas mixing in this study are 0.001 and $0.005 \mathrm{~m}$, respectively, Eq. (27) is given

$$
\left.\beta\left(a_{\mathrm{i}}, d_{\mathrm{B}}\right)\right|_{\mathrm{RH}} /\left.\beta\left(a_{\mathrm{i}}, d_{\mathrm{B}}\right)\right|_{\mathrm{gas}} \propto\left(\frac{0.001}{0.005}\right)^{-0.073}=1.12 \ldots
$$

where $\left.\beta\left(a_{\mathrm{i}}, d_{\mathrm{B}}\right)\right|_{\mathrm{i}}$ is $\beta\left(a_{\mathrm{i}}, d_{\mathrm{B}}\right)$ of the $\mathrm{i}(\mathrm{i}=\mathrm{RH}$, gas) mixing. The smaller agglomeration rate of the RH mixing resulted 

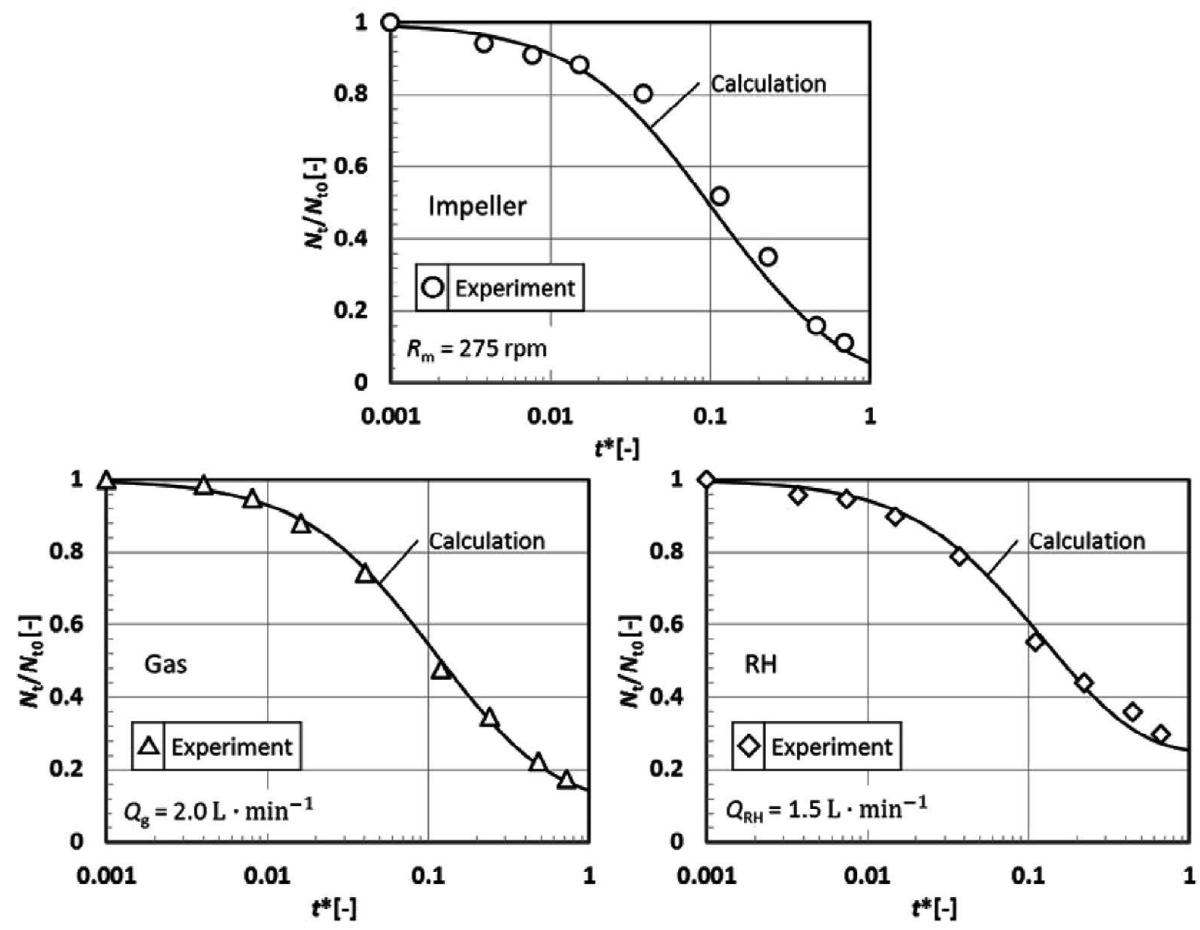

Fig. 11. Prediction of temporal change in number of clusters of all particles for impeller, gas and RH mixing at energy input rate of $0.027 \mathrm{~W} \cdot \mathrm{kg}^{-1}$.
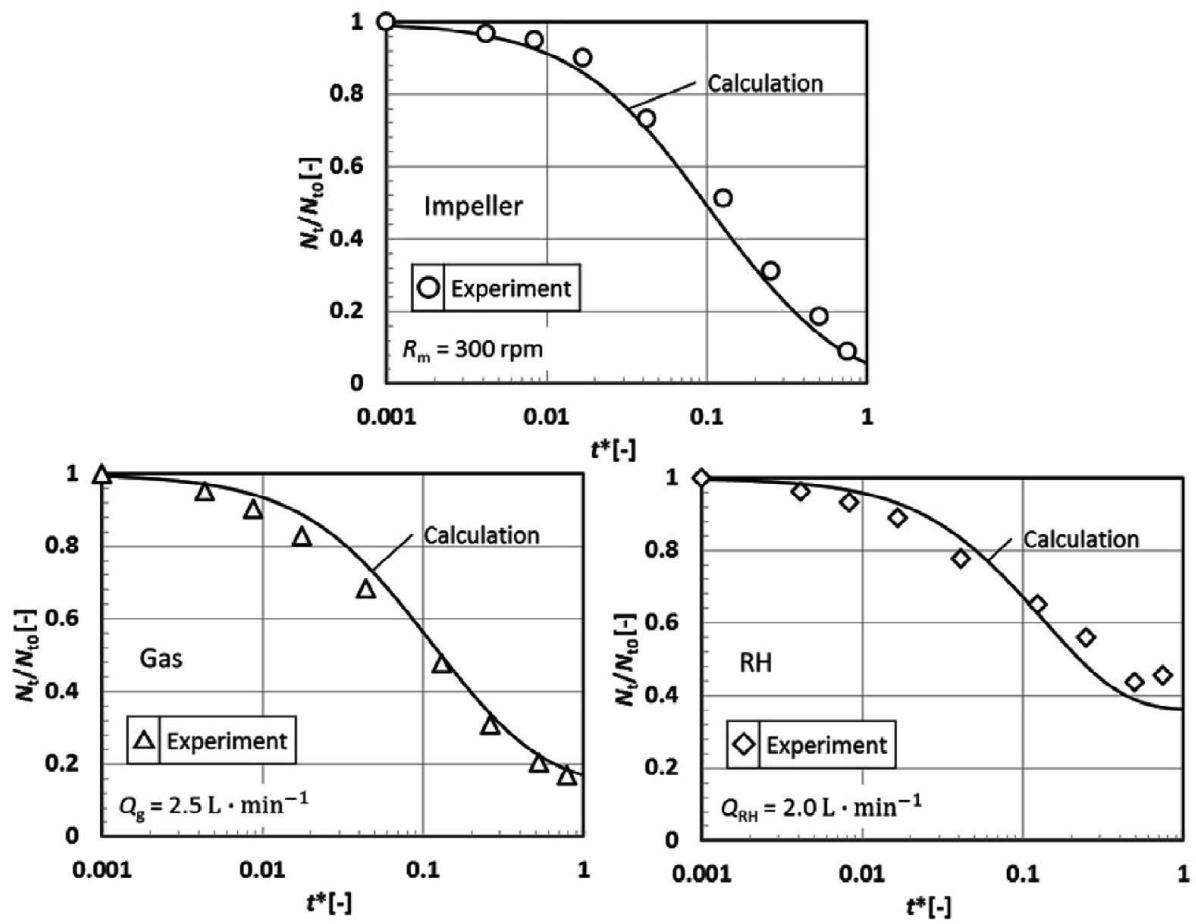

Fig. 12. Prediction of temporal change in number of clusters of all particles for impeller, gas and RH mixing at energy input rate of $0.035 \mathrm{~W} \cdot \mathrm{kg}^{-1}$.

from the smaller diameter and larger gas velocity through the nozzle.

The experimental results of the impeller mixing were explained only by the particle agglomeration model as described in Section 4.2.1, whereas those of the gas and RH mixings were interpreted by the addition of the breakup model of agglomerated particles. Thus, as shown in Fig. 4, the slightly less agglomeration rate of the impeller mixing than that of the gas mixing or the same level was attributed to the smaller breakup rate of agglomerated particles for the gas mixing. On the other hand, the overall agglomeration rate of the RH mixing was smaller than that of the gas mixing due to the larger $\beta\left(a_{\mathrm{i}}, d_{\mathrm{B}}\right)$ value, that is, the greater breakup rate of the agglomerated particles of the RH condition in this study.

Thus, the agglomeration behavior of fine particles was predicted by the newly developed mathematical model including not only the agglomeration but also the breakup of particles under the different mixing patterns. 


\section{Conclusions}

Model experiments on the agglomeration and breakup behavior of fine particles in liquid among different mixing operations, that is impeller (impeller), gas blow mixing (gas), and gas and liquid jet blow mixing by RH degasser (RH) mixing, were carried out and a mathematical model was developed and compared with them. Results obtained in this study were as follows.

(1) Total number of particles at each mixing process decreased with the increasing time, although the agglomeration rate decreased.

(2) The agglomeration rate of particles at the same mixing energy input in the liquid was in the following decreasing order: impeller $>$ gas $>$ RH mixing.

(3) The experimental results of the impeller mixing were able to be explained by turbulence agglomeration model.

(4) A breakup model of particles was developed assuming that the agglomerated particles adhered to the surface of bubbles during bubble floating in the liquid was divided into two pieces on the gas/liquid free surface at the moment of bubble bursting.

(5) By introducing this breakup model in addition to the agglomeration one, the calculation for both of the gas and RH mixing agreed well with the experimental results.

\section{REFERENCES}

1) H. Ling, L. Zhang and H. Li: Metall. Mater. Trans. B, 47B (2016), 2991.

2) H. Yin, H. Shibata, T. Emi and M. Suzuki: ISIJ Int., 37 (1997), 936

3) K. Okumura, M. Hirasawa, M. Sano, K. Mori, N. Hakamada and M. Kitazawa: ISIJ Int., 35 (1995), 826

4) L. Claudotte, N. Rimbert, P. Gardin, M. Simonnet, J. Lehmann and B. Oesterle: AIChE J., 56 (2010), 2347.

5) T. Li, S. Shimasaki, S. Taniguchi, K. Uesugi and S. Narita: ISIJ Int., 53 (2013), 1943.

6) C. Lee and T. A. Kramer: Adv. Colloid Interface Sci., 112 (2004), 49.

7) T. Tozawa, Y. Kato, K. Sorimachi and T. Nakanishi: ISIJ Int., 39 (1999), 426.
8) S. Sato, M. Kobayashi and Y. Adachi: J. Colloid Interface Sci., 272 (2004), 345

9) T. Li, S. Shimasaki, S. Taniguchi, K. Uesugi and S. Narita: ISIJ Int., 53 (2013), 1958

10) T. Fukasawa and Y. Adachi: J. Colloid Interface Sci., 304 (2006), 115.

11) Y. Adachi, M. Kobayashi and S. Oi: J. Colloid Interface Sci, 208 (1998), 353.

12) M. Cournil, F. Gruy, P. Gardin and H. Saint-Raymond: Chem. Eng. Process., 45 (2006), 586.

13) T. Nakaoka: Kobe Steel Eng. Rep., 56 (2006), 40.

14) H. Arai, Y. Nakamura, S. Shimasaki and S. Taniguchi: Tetsu-toHagané, 101 (2015), 57.

15) H. Arai, Y. Nakamura, S. Shimasaki and S. Taniguchi: Tetsu-toHagané, 101 (2015), 67.

16) M. Cerbelaud, A. Videcoq, P. Abelard, C. Pagnoux, F. Rossignol and R. Ferrando: Langmuir, 24 (2008), 3001.

17) M. Kobayashi: J. Appl. Mech., 11 (2008), 517.

18) S. Rollié, H. Briesen and K. Sundmacher: J. Colloid Interface Sci., 336 (2009), 551

19) K. Higashitani, K. Yamaguchi, Y. Matsuno and G. Hosokawa: J. Chem. Eng. Jpn., 16 (1983), 299.

20) M. Kobayashi and Y. Adachi: Trans. Jpn. Soc. Irrig. Drain. Reclam. Eng., 191 (1997), 111.

21) T. Nakaoka, S. Taniguchi, K. Matsumoto and S. Johansen: ISIJ Int., 41 (2001), 1103.

22) D. R. Vigil, I. Vermeersch and R. O. Fox: J. Colloid Interface Sci., 302 (2006), 149

23) T. Nakaoka, K. Matsumoto and S. Taniguchi: Prog. Comput. Fluid Dyn. Int. J., 8 (2008), 270.

24) S. T. Johansen and S. Taniguchi: Light Metals Proc., TMS, Warrendale, PA, (1998), 855.

25) T. Fujii and I. Muchi: Tetsu-to-Hagané, 55 (1969), S124.

26) Y. Kato, H. Nakato, T. Fujii, S. Ohmiya and S. Takatori: ISIJ Int., 33 (1993), 1088.

27) Chemical Engineering Handbook, ed. by The Society of Chemical Engineers, Japan, Maruzen, Tokyo, (2011), 339.

28) M. Sano and K. Mori: Tetsu-to-Hagané, 68 (1982), 2451.

29) M. V. Smoluchowski: Z. Phys. Chem., 92 (1917), 129.

30) P. G. Saffman and J. S. Turner: J. Fluid Mech., 1 (1956), 16.

31) K. Higashitani, K. Yamauchi, Y. Matsuno and G. Hosokawa: J. Chem. Eng. Jpn., 16 (1983), 299.

32) A. V. Nguyen and S. Kmet: Int. J. Miner. Process., 40 (1994), 155.

33) B. Pyke, D. Fornasiero and J. Ralston: J. Colloid Interface Sci., 265 (2003), 141.

34) H. Arai, A. Matsumoto, S. Shimasaki and S. Taniguchi: ISIJ Int., 49 (2009), 965.

35) M. Iguchi and T. Chihara: Jpn. J. Multiph. Flow, 11 (1997), 46.

36) L. Davidson and E. H. Amick: AIChE J., 2 (1956), 337.

37) M. Sano and K. Mori: Tetsu-to-Hagané, 60 (1974), 348.

38) Chemical Engineering Handbook, ed. by The Society of Chemical Engineers, Japan, Maruzen, Tokyo, (2011), 698. 